\title{
PECULIARITIES OF FIRE-CRACKER PLATE ELECTRODE ARC SURFACING OVER ALLOYING CHARGE
}

\author{
I.A. BARTENEV \\ Karaganda State Technical University \\ 56 Mir Bld., 100027, Karaganda, Kazakhstan. E-mail: igor_svar@mail.ru
}

\begin{abstract}
The method of arc surfacing of flat parts using fire-cracker plate electrode over alloying charge was offered. The main factors determining stability of surfacing process are the following: arc voltage $U$, arc current $I$, and electrode sectional area $S$. As a result of experiments the range of surfacing current (300-400 A) was determined providing stability of mode at the start and throughout the whole process of surfacing. It was established that hardness of deposited metal amounted to HRC 47-52, which is higher than that of metal such as steel G13. Metallographic investigations showed that the offered method provides a minimal penetration of base metal, that will allow obtaining the necessary chemical composition of deposited metal in single-layer surfacing. 4 Ref., 2 Tables, 3 Figures.
\end{abstract}

Key words: arc surfacing, alloying charge, plate electrode, hardness of deposited metal, penetration

High-manganese austenitic steels, containing up to $13 \% \mathrm{Mn}$ and known under the grade of Hadfield steel, are widely used in manufacture and restoration of parts operating at abrasive wear with intensive impact loads [1, 2]. In particular, they are used in manufacture of parts of crushing and milling equipment, railroad frogs, excavator bucket teeth, etc. Steels of this type have an ability to cold working under the effect of impact loads, whereby hardness of surface of parts manufactured of these steels increases to $H B$ 450-500, while their core remains tough and its hardness is at the level of $H B$ 220-280.

To restore parts of high-manganese steels the arc surfacing using flux-cored wire gained the widest use in industry $[3,4]$. The chemical composition and hardness of metal deposited by these wires are shown in Table 1.

Comparing chemical compositions of manganese steels and those of standard ferromanganese (Table 2), it can be assumed that in the general weld pool by mixing low-carbon steel and ferromanganese in specific proportions a composition can be provided similar, for example, to steel of G13 type.

To realize this possibility the most appropriate is the method of arc surfacing using fire-cracker plate electrode over the alloying charge in the form of carbon ferromanganese alloy (Figure 1). In this case surfacing is carried out under flux by ignition of arc between the workpiece being surfaced and the plate placed on layer of alloying filler of $3-5 \mathrm{~mm}$ thickness (see Figure 1). The arc at the rate of melting electrode and filler moves along the part, and as a result, a highlyalloyed deposited metal bead is formed on its surface. With a proper preparation the surfacing process is rather stable.

To implement the proposed technology the related experiments were conducted. On the specimen of steel St3 of the size $300 \times 150 \times$ $\times 10 \mathrm{~mm}$ a layer of flux AN-348A of $3 \mathrm{~mm}$ thickness was uniformly poured, with an area corresponding to that of the plate electrode. Atop the flux a plate electrode was horizontally placed, over which the powder alloying filler was poured. In the experiments as alloying filler the alloy of the following composition was used, wt.\%: $1.7 \mathrm{C}$; $86 \mathrm{Mn} ; 2 \mathrm{Si} ; \mathrm{Fe}$ - the rest. Over the alloying

Table 1. Chemical composition and hardness of deposited metal of the type of high-manganese austenite steels

\begin{tabular}{|c|c|c|c|c|c|c||}
\hline \multirow{2}{*}{$\begin{array}{c}\text { Type of deposited } \\
\text { metal }\end{array}$} & \multicolumn{7}{|c||}{ Mass fraction of elements, \% } & \multicolumn{2}{c||}{ Hardness $H B$} \\
\cline { 2 - 7 } & $\mathrm{C}$ & $\mathrm{Si}$ & $\mathrm{Mn}$ & $\mathrm{Cr}$ & $\mathrm{Ni}$ & After surfacing \\
\hline G13 & 1.0 & 0.6 & 13 & - & - & $220-280$ \\
\hline G13N4 & 0.8 & 0.5 & 13 & - & 4 & $170-230$ \\
\hline G13Kh25N3 & 0.8 & 0.4 & 14 & 25 & 3 & $220-320$ \\
\hline
\end{tabular}


Table 2. GOST 4755-91: Ferromanganese. Technical requirements and delivery conditions

\begin{tabular}{|c|c|c|c|c|c|c|c|}
\hline \multirow{4}{*}{ Group of materials } & \multirow{4}{*}{ Grade of alloy base } & \multicolumn{6}{|c|}{ Mass fraction, $\%$} \\
\hline & & \multirow{3}{*}{$\mathrm{Mn}$} & \multirow{2}{*}{$\mathrm{C}$} & \multirow{2}{*}{$\mathrm{Si}$} & \multicolumn{2}{|c|}{$\mathrm{P}$} & \multirow{2}{*}{$\mathrm{S}$} \\
\hline & & & & & $A$ & $B$ & \\
\hline & & & \multicolumn{5}{|c|}{ Not more than } \\
\hline Low-carbon & FMn90 & $\geq 85-95$ & 0.5 & 1.8 & 0.05 & 0.3 & 0.02 \\
\hline Medium-carbon & FMn88 & $\geq 85-95$ & 2.0 & 3.0 & 0.10 & 0.4 & 0.02 \\
\hline \multirow[t]{2}{*}{ High-carbon } & FMn78 & $\geq 75-82$ & 7.0 & 6.0 & 0.05 & 0.7 & 0.02 \\
\hline & FMn70 & $\geq 65-75$ & 7.0 & 6.0 & 0.30 & 0.7 & 0.02 \\
\hline
\end{tabular}

filler the second layer of flux AN-348A of up to $2 \mathrm{~cm}$ height was poured.

The electric arc surfacing was performed in laboratory installation using a «hard» start. As power source, rectifier VDM-1202S with rigid external current-voltage characteristic was used. As plate electrodes the strips of steel St3 were used. Mass of the surfacing powder of manganese alloy varied in the range of $20-50 \mathrm{~g}$.

The greatest problems in implementation of surfacing process arose at the start. It was established that the main factors determining stability of the process at the start are the following: arc voltage $U$, arc current $I$, and electrode sectional area $S$.

During experiments, at the start the parameters of surfacing mode were changed within the following limits: surfacing current from 280 to $350 \mathrm{~A}$, voltage from 28 to $36 \mathrm{~V}$, and section of plate electrode from 50 to $80 \mathrm{~mm}^{2}$. As a result of surfacing the deposited beads of 15-25 mm width and 5-8 $\mathrm{mm}$ height were produced. The specimens were cut out of them to investigate microstructure and determine hardness of deposited layer.

As a result of experiments the range of surfacing current was determined (300-400 A) providing stability of the mode at the start and throughout the whole process of surfacing. At current of less than 300 A a lack of fusion of the

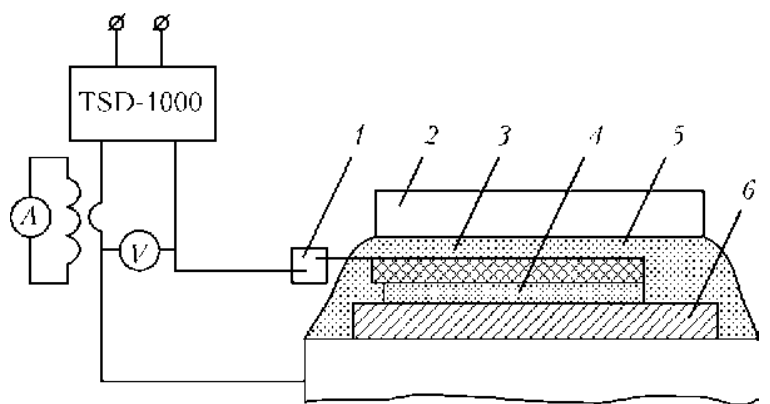

Figure 1. Fire-cracker plate electrode surfacing over the alloying filler layer: 1 - current conductor; 2 - copper plate; 3 - electrode; 4 - alloying filler; 5 - flux; 6 workpiece deposited bead along its edges was observed due to insufficient heat input to the part being surfaced. By increasing current over $400 \mathrm{~A}$ due to high rate of surfacing the process of starting operation was difficult to control, which resulted often in short circuiting of electrode to the part being surfaced.

While conducting experiments it was established that the hardness of deposited metal amounted to $H R C$ 47-52, which is higher than that of metal such as steel G13. Moreover, chemical composition and hardness of the deposited
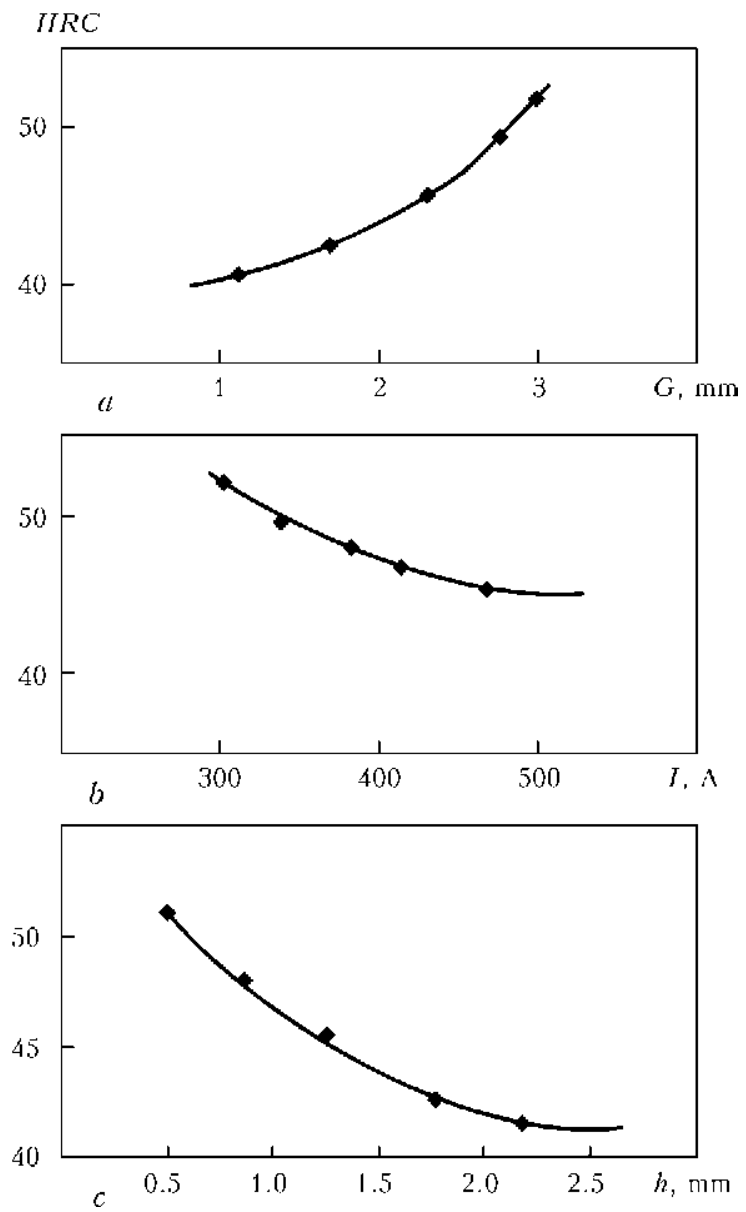

Figure 2. Dependence of deposited metal hardness on thickness of layer $G$ of alloying filler $(a)$, surfacing current $I$ (b) and penetration depth $h(c)$ 


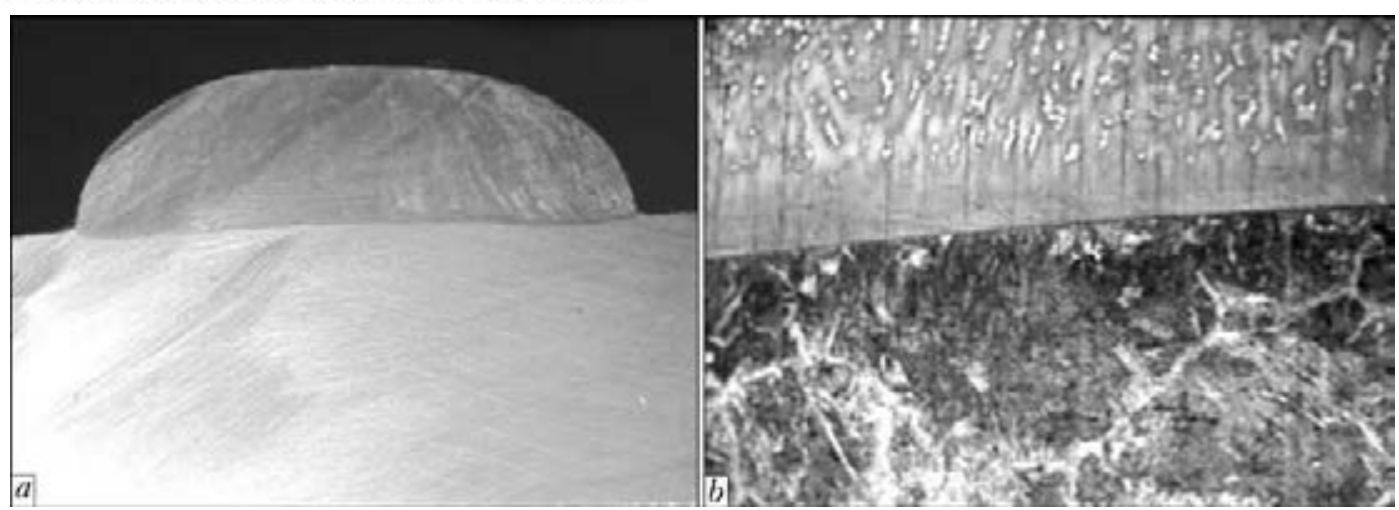

Figure 3. Macrosection $(a)$ and microstructure $(b)$ of deposited specimen

metal are affected by mass, and in this case, by thickness of alloying filler layer per unit of length of deposited bead. With increase in the layer thickness the hardness is increased and during its decrease the latter decreases respectively ( $\mathrm{Fi}$ gure $2, a$ ).

With increase in surfacing current the hardness of deposited metal is reduced (Figure 2, $b$ ). This is explained by increase in current with increase in penetration depth, which leads to increase in the proportion of base metal in the deposited metal and corresponding decrease in hardness of the deposited metal (Figure 2,c).

Metallographic investigations showed that the offered method provides a slight penetration of the workpiece surface. Along the edges of deposited bead the penetration is higher at the clear fusion boundary and minimum fusion in the middle part of bead section (Figure 3, $a$ ).

In the microstructure of deposited metal (Figure $3, b$ ) very fine dendrites are observed grow- ing from the surface of base metal with a high content of austenite and martensite.

Thus, as a result of experiments, the parameters of stable arc surfacing process using firecracker plate electrode over alloying charge were determined. As the alloying filler charge it was proposed to use powder of carbon ferromanganese. The developed process can be used in wearresistant surfacing of flat parts.

1. Vlasov, V.M. (1987) Serviceability of reinforced friction surfaces. Moscow: Mashinostroenie.

2. Livshits, L.S., Grinberg, N.A., Kurkumelli, E.G. (1969) Principles of alloying of deposited metal. Moscow: Mashinostroenie.

3. Frumin, I.I. (1961) Automatic electric arc surfacing. Kharkov: Metallurgizdat.

4. Ryabtsev, I.A., Kondratiev, I.A. (1999) Mechanized electric arc surfacing of metallurgical equipment parts. Kiev: Ekotekhnologiya.

Received 20.04.2015 